\title{
"Como é linda a minha aldeia": o papel dos gêneros musicais massivos na construção de uma imagem mítica de Portugal
}

\author{
Tiago José Lemos Monteiro
}

\section{Resumo}

0 objetivo deste paper é investigar em que medida alguns gêneros musicais populares massivos e midiáticos atuaram no sentido de reforçar uma determinada imagem mítica de Portugal, associada à condição de destino turístico ou direcionada à comunidade migrante residente no exterior, sobretudo durante a última década do Salazarismo (1964-1974) e também ao longo do decênio posterior. Inicialmente, busco estabelecer uma conexão entre 0 imaginário simbólico consagrado nessa época e as representações hegemônicas sobre Portugal que hoje circulam nas revistas e cadernos de turismo, notadamente naqueles cujo foco é a capital Lisboa. Em um segundo momento, tendo em vista nosso (des)conhecimento da produção musical portuguesa contemporânea, discuto como a predominância de formatos enquadrados naquilo que se consagrou como nacional-cançonetismo está intimamente relacionada à perpetuação de alguns "recortes" estereotipizantes sobre Portugal, associada, quase sempre, a iniciativas de caráter político e mercadológico.

\section{Palavras-chave}

Relações Brasil-Portugal. Música Popular Massiva. Nacional-cançonetismo. Estereótipo. Salazarismo.

Tiago José Lemos Monteiro | tjimonteiro@yahoo.com.br Doutorando em Comunicação Social pela Universidade Federal Fluminense - UFF.

\section{Considerações iniciais}

Português teu passaporte/ Já nem é preciso ter/ Porque Deus já deu a sorte/ De nasceres português/ [...]/ Tu tens na cara um sorriso triste/ $\mathrm{E}$ quem resiste a esse teu olhar/ Que às vezes fala de uma saudade/ De outro tempo ou de algum lugar/ [...]/ E mesmo pobre, quando pões a mesa/ Pões a fartura de tudo o que tens/ Nossa Senhora reza do azulejo:/ "Eu te projeto, bom português" ("Português sem passaporte" in Roberto Leal [1983]).

0 objetivo deste artigo é investigar em que medida alguns gêneros musicais populares massivos e midiáticos atuaram no sentido de reforçar uma determinada imagem mítica de Portugal, associada a sua condição de destino turístico ou direcionada à comunidade migrante residente no exterior. Embora tal imagem seja 0 resultado de uma estratégia iniciada durante a vigência do Estado Novo salazarista e consolidada ao longo da última década do Regime (19641974), percebe-se que esse imaginário continuou a ser perpetuado mesmo após a Revolução dos Cravos (abril de 1974) e no decênio seguinte.

Se nos propusermos a refletir, durante breves dois minutos, a respeito das imagens e representações 
que associamos a Portugal, talvez sequer problematizemos a frequência com que certas "marcas de passado" são acionadas, de tão naturalizadas que tais formas se constituíram. A cultura portuguesa é invariavelmente concebida a partir de referências que, na melhor das hipóteses, datam da década de 50 do século passado.

Quando pensamos em Portugal na condição de destino turístico, são os azulejos, as quintas, os vinhedos, os castelos, o velho casario do Porto, os bonecos típicos em miniatura e os souvenirs do Santuário de Fátima que predominam sobre as auto-estradas, os centros comerciais, os trens de alta velocidade e as construções modernas, como o Oceanário de Lisboa ou o Pavilhão da Expo (MONTEIRO, 2008a; 2008b).

As recentes aparições de Portugal nos programas de televisão e suplementos turísticos dos jornais brasileiros de grande circulação ainda parecem bastante vinculadas à imagem consagrada entre nós ao longo das últimas décadas. Como os atuais intercâmbios simbólicos entre os dois países primam pela ideia de assimetria ou pela existência de incontáveis ruídos, restam os laços históricos que já duram mais de 500 anos a unir as duas nações, razão pela qual apenas efemérides como a celebração do nosso Descobrimento ou dos dois séculos da chegada da corte de Dom João VI parecem capazes de trazer Portugal e a cultura portuguesa de volta à nossa mídia.

Como ponto de partida da reflexão, busco estabelecer uma conexão entre o imaginário simbólico consagrado entre os brasileiros e as representações mais comuns sobre Portugal que hoje circulam nas revistas e cadernos de turismo. Mantenho o foco na capital, Lisboa, sem desconsiderar que o imaginário turístico associado a Portugal mistura indiscriminadamente elementos de regiões, culturas e, em certa medida, "sensos comuns" distintos entre si (possibilitando que a trilha sonora de um passeio pelas praias do Algarve seja algo próximo do vira minhoto, conforme demonstrado por recente edição do programa SBT Repórter sobre Portugal). Aqui, 0 interese residirá menos nas permanências e rupturas em relação a esse imaginário, e mais nos modos pelos quais os discursos hegemônicos da tradição se articulam a quadros de modernidade cada vez mais imperativos no olhar jornalístico contemporâneo sobre Portugal.

Em um segundo momento, utilizo como corpus de investigação 0 acervo de LPs da loja Modern Sound, situada no bairro de Copacabana (Rio de Janeiro): a partir de uma análise detalhada da seção de música portuguesa deste estabelecimento, foi possível perceber como a predominância de formatos enquadrados naquilo que se consagrou como nacional-cançonetismo está intimamente relacionada à perpetuação de alguns "recortes" estereotipizantes sobre Portugal, associada, quase sempre, a iniciativas de caráter ao mesmo tempo político (quando sob a chancela do Secretariado Nacional de Informação) e mercadológico, num contexto posterior aos acontecimentos de Abril. 


\section{2 "Formas tradicionais" e "quadros de modernidade" nas representações de Lisboa em periódicos turísticos - um ponto de partida}

0 objetivo desta seção é verificar em que medida 0 supracitado imaginário turístico - tão profundamente associado às formas tradicionais e míticas de uma certa cultura lusitana - passa a ser cada vez mais tensionado pela intromissão de diversos quadros de modernidade, vinculados à entrada de Portugal na União Europeia, aos fluxos globais de pessoas e significados e à condição de fronteira semi-periférica ocupada pelo país nessa dinâmica (SANTOS, 2006). 0 corpus da análise é constituído pelas matérias "Portugal barato" (revista Minha Viagem, jun. 2008) e "Da Baixa ao Alto" (caderno Boa Viagem, jornal O Globo, jul. 2008), bem como pela edição especial "Isto é Portugal" da revista Viagem e turismo (maio 2008). Os três veículos dedicam uma média de 12 páginas, cada um, à cidade de Lisboa.

Comparando-se as três matérias, a abordagem da revista Viagem e turismo é a que mais se pauta pela exaltação das formas tradicionais, direcionamento explícito já a partir dos títulos das seções. "Melancolia" e "Alma" são os termos usados para nomear, respectivamente, um ensaio fotográfico sobre casas de fado e uma reportagem sobre Lisboa que reúne depoimentos de escritores, fotógrafos e artistas plásticos que nasceram ou moram na capital portuguesa, e cujo tom é mais impressionista do que factual, o que talvez explique 0 tom mítico de algumas falas: "Lisboa é uma cidade onde se encontram anjos a pairar nas esquinas" (REIS, 2008); "As sete colinas de Lisboa [...] descem sobre o mar à procura de amor eterno" (HONRADO, 2008); "Lisboa fica no sangue" (QUEIROZ, 2008), entre outras. 0 único trecho no qual se identifica a intromissão de eventuais quadros de modernidade é na descrição do processo através do qual "as alfacinhas passaram dos xales negros e das sabrinas de ráfia aos fuck me shoes e clutchs, do buço à civilização do Sex \& the city" (SALAZAR, 2008), que, no entanto, não deixa de interpelar alguns elementos da ordem do estereótipo.

Avaliação semelhante pode ser feita da matéria da revista Minha viagem: menos poética do que a abordagem anterior e mais calcada no fornecimento de dicas que barateiem a viagem do leitor - "em comparação com Inglaterra, Alemanha, Itália, [...] se gasta menos fazendo turismo na terrinha. [...] Agradeça ao real forte que deixou Portugal mais acessível" (PORTAS, 2008) - tanto as ilustrações quanto os textos escritos privilegiam a dita "tradição" dos passeios pela região da Alfama, com suas roupas penduradas nos varais e as habituais casas de fado. A despeito de uma imagem de Fernando Pessoa grafitada num muro lisboeta e de uma breve nota de rodapé sobre a área do Parque das Nações (que, contudo, fica "relativamente longe do que interessa"), é a 
bordo do Eléctrico $\mathrm{n}^{0} 28^{1}$ que se conhece a Lisboa da revista Minha viagem.

Contrapondo-se radicalmente aos dois veículos abordados nos parágrafos anteriores, alguns trechos da reportagem "Fado moderno à beira do Tejo" do suplemento Boa Viagem (jornal $O$ Globo) propõem um olhar sobre Lisboa que, sem desconsiderar a finalidade turística das informações fornecidas, adota uma estratégia dialógica em relação às formas tradicionais e aos quadros de modernidade, constituindo uma bem vinda exceção. Estão lá os bondes, os castelos, as antigas casas de comércio e, sobretudo, num tratamento mais para 0 afetivo do que para 0 anedótico, os costumes idiossincráticos do povo português: no entanto, também aparecem as lojas de design, moda, acessórios e decoração (como Maomao, Happy Days, Hold Me e The Wrong Shop!, onde é possível encontrar desde camisetas com estampas pop até Galos de Barcelos em versão gay friendly), os cafés e terraços frequentados pela juventude lisboeta e as casas de fado "vadio", como a Tasca do Chico locais ainda relativamente à margem do circuito turístico hegemônico.

Como se vê, a despeito das eventuais intromissões de determinados quadros de modernidade, é através da mediação das formas tradicionais que percebemos a cultura portuguesa. Nas próximas seções, dedico-me a investigar em que medida a fossilização desse imaginário pode ser vinculada à promoção sistemática de alguns conteúdos musicais.

\section{3 "É tão bom ser pequenino": a construção político-mercadológica de um Portugal mítico}

Em sintonia com outros fascismos europeus, pelo menos no que diz respeito à busca obsessiva pelas "autênticas raízes" da Nação, bem como no apelo sistemático a um passado de glórias no qual repousariam as evidências incontestáveis de um futuro grandioso, o discurso oficial do Estado Novo Salazarista consistia, em linhas gerais, na exaltação de todos os valores que fossem percebidos como características singulares do povo português. Coube ao Secretariado de Propaganda Nacional viabilizar esse discurso sob a forma de iniciativas culturais diversas. Criado em 1933, o Secretariado de Propaganda Nacional era o órgão público responsável pelas atividades de propaganda política, comunicação social, turismo, informação e cultura durante o regime do Estado Novo. Em 1945, teve seu nome alterado para Secretariado Nacional de Informação, Turismo e Cultura Popular, ou simplesmente SNI ${ }^{2}$. Durante seu período mais representativo, entre 1933 e 1950, quando esteve sob a chefia de António Ferro

0 eléctrico no. 28 vai do Largo do Martim Moniz ao Campo de Ourique, passando pela Alfama, Castelo de São Jorge, Baixa e subindo 0 Chiado, sendo, por isso, bastante requisitado pelos turistas.

Houve ainda uma terceira mudança de nome, em 1968, quando o SNI passou a se chamar Secretaria de Estado de Informação e Turismo. 
[o SNI] organizou várias exposições de arte popular, promoveu o concurso da aldeia mais portuguesa, editou livros de temática etnográfica, lançou espetáculos e palestras com dança e música populares, tentou estabelecer um estilo decorativo contemporâneo inspirado nos motivos rústicos, [e] criou os bailados Verde-Gaio, companhia de dança marcada por um repertório de cariz folclórico (ALVES, 2007, p. 1).

0 projeto desenvolvimentista de Salazar convivia com a defesa de uma concepção engessada de tradição, segundo a qual residiria na imutabilidade de certas formas culturais o caráter singularizador de uma identidade nacional forte. Não por acaso, tanto a política cultural interna do Estado Novo quanto a externa, centralizada em torno do SNI, concentraram-se na defesa de uma suposta autenticidade da cultura das aldeias, do folclore do interior (da região das Beiras, do Minho, do Alto Douro e do Alentejo, de forma precípua) sobre a cultura "contaminada" da classe média urbana - a mesma que funcionava como principal pilar de sustentação ideológico do salazarismo.

A apropriação empreendida pelo regime, entretanto, solapava os processos sociais, históricos e simbólicos que deram origem a essas formas, retendo apenas os elementos pitorescos desse "Portugal profundo" mitificado que, longe de evidenciarem o seu caráter mutável, acabavam por consolidar seu fabuloso anacronismo, criando, assim, um "perfil idílico da nação, [...] encenador do mundo campestre das aldeias, inventor de ranchos folclóricos e de galos de Barcelos" (ALVES, 2007, p. 1).

Há que se destacar, no entanto, que as estratégias folcloristas empreendidas pelo SNI de António Ferro não eram direcionadas eminentemente para as classes populares, "produtoras" das formas que 0 regime apropriava, mas sim às classes médias e camadas mais altas da sociedade portuguesa, bem como ao público estrangeiro, sobretudo em sua condição de migrante $^{3}$ ou turista, reforçando a ideia de que toda identidade nacional depende de legitimação externa para se afirmar (ALVES, 2007). Para que tal objetivo fosse alcançado, era preciso mobilizar toda uma infra-estrutura de mídia e propaganda que, embora incipiente em Portugal àquela altura, revelou-se capaz de atuar nos mais diversos campos culturais ${ }^{4}$.

Vale lembrar que as décadas de 40 e 50 correspondem ao momento no qual o fluxo emigratório português foi mais intenso durante 0 século XX, e que a promoção destes conteúdos musicais, somada ao controle do tráfego de informações entre Portugal e Brasil efetuado pelo regime, terminava por perpetuar a imagem de um país igualmente mítico e preservado no tempo, tornado possivvel graças aos esforços do regime salazarista, revelando-se, por isso, politicamente estratégica.

Shaw (2007) e Granja (2007), por exemplo, dedicam-se a investigar o papel de alguns dos exemplares mais populares do cinema português dos anos 40 e 50 na consolidação de um imaginário profundamente conformista, no qual o meio rural é representado como um espaço de paz e concórdia, embora por vezes desigual e miserável (Aldeia da roupa branca, 1938), e em que os conflitos sociais no ambiente urbano são, em regra, resolvidos através de um "bom casamento" ( 0 leão da estrela, 1947). Embora tais filmes, hoje, pareçam excessivamente ingênuos e desprovidos de um caráter propagandístico mais explícito, é possível perceber como, nos entreframes da "comédia à portuguesa", são reproduzidos alguns dos principais pilares do discurso oficial do regime. 
No que diz respeito à música produzida e difundida durante esse período, cabe questionar: no contexto da política cultural salazarista, que gêneros musicais seriam esses? Para fins deste paper, restrinjo o foco da minha abordagem àquilo que ficou consagrado como nacionalcançonetismo. A expressão define, a princípio, as canções e 0 tipo de música que 0 regime salazarista apoiava e cuja execução incentivava, nas emissoras de rádio e televisão, bem como no que dizia respeito às edições discográficas. Coube ao nacional-cançonetismo ajudar a reproduzir uma série de estereótipos do nosso "senso comum mítico" sobre Portugal (SANTOS, 2006), entre eles a figura do português "pobre, mas honrado" e da "casa portuguesa com certeza", que se apoiavam na exaltação de banalidades e assim ajudavam a obscurecer a real situação política e econômica do país.

Os elementos constituintes desse senso comum mítico, por sua vez, estariam diretamente relacionados a algumas variáveis históricas, políticas e sociais (que vão desde a figura do Navegador consagrada à época dos Descobrimentos até os eventos que cercam o desaparecimento de D. Sebastião) a partir das quais uma certa narrativa nacional portuguesa, que acabou por se tornar hegemônica, foi escrita ao longo dos séculos (MONTEIRO, 2008b).

Curioso é perceber como certas percepções míticas transbordam, inclusive, para 0 âmbito das Ciências Sociais, cujo esforço deveria ser no sentido de desconstruir tais discursos. É imbuído desse espírito que um antropólogo como Jorge Dias (apud SANTOS, 2006, p. 59-60), por exemplo, vai definir a "personalidade de base" dos portugueses a partir de características como as virtudes da abnegação e do sacrifício, uma "enorme capacidade de adaptação a todas as coisas, ideias e seres", "um vivo sentido da natureza, $[. .$.$] um fundo poético e$ contemplativo" e, por fim, o fato de o português "colocar o coração acima de todas as coisas". 0 imaginário nacional-cançonetista, por sua vez, não ocasionalmente efetuará apropriações deste discurso, em textos de apresentação de álbuns no qual o português é retratado como alguém que

faz da terra o seu leito de nações. Estende não apenas as fronteiras de sua pátria, mas as fronteiras do seu corpo, sob o céu da nova pátria, que continua a ser a mesma. Leva e impõe, rudemente, os mesmos hábitos, o mesmo idioma, a mesma ternura ou o mesmo carinho áspero como sua pele. 0 português acredita que a humanidade, como 0 amor, é universal. 0 português acredita, como as Escrituras, que de um sangue são todas as nações dos homens (David Nasser in Portugal do meu amor, trilha sonora original do filme de Jean Manzon, 1967).

No entanto, é preciso delimitar melhor as particularidades desse estilo musical: ele seria "nacional" em virtude da promoção sistemática de valores compreendidos como essenciais do caráter português, conforme a cartilha do Estado Novo; e "cançonetista" por se apoiar no formato canção - sobretudo o da chanson francesa, com suas orquestrações e harmonias características 
- e plasmá-la a determinados elementos da música tradicional e/ou folclórica portuguesa, como a guitarra ou a concertina, numa espécie de síntese entre o rural e 0 urbano que garantia a essa música uma projeção midiática considerável. Isso nos permite concluir, pelo menos em um primeiro momento, que o nacional-cançonetismo talvez seja menos um gênero em si e mais um modo de operacionalização estratégica de outros gêneros musicais, conforme atestam inúmeras das coletâneas que serão analisadas na próxima subseção deste paper. Da mesma forma, evita que confundamos o nacional-cançonetismo com todo e qualquer conteúdo musical promovido durante o período do Estado Novo: embora 0 fado e o folclore também tenham desempenhado esse papel, pode-se dizer que estes envolvem aspectos técnico-formais, dinâmicas de produção e circulação e estratégias de conformação de sentido relativamente distintos ${ }^{5}$.

Após a queda do regime, em 25 de abril de 1974, Portugal experimentou um breve período de euforia política que, no âmbito cultural, traduziu-se num aumento da presença midiática dos artistas de intervenção. Com a contrarevolução de novembro de 1975, que pôs um freio na pretensão socialista do Movimento dos
Capitães, reascendeu ao poder uma corrente política mais conservadora e disposta a ampliar a abertura (sobretudo econômica) de Portugal para o restante da Europa. Nesse contexto, paralelo à penetração, cada vez maior, da música popular massiva de origem anglófona (que ajuda a explicar, entre outros fatores, o boom do pop/rock português dos anos 80), consolidase uma nova forma de nacional-cançonetismo, agora atendendo a disposições eminentemente mercadológicas e atrelado à sedimentação da imagem de Portugal como destino turístico (CORREIA, 1984). 0 exemplo mais representativo do neo-nacional-cançonetismo talvez seja 0 cantor Roberto Leal, muito popular no Brasil durante os anos 80 .

\section{Portugal, um "jardim musical"6: análise do discurso (neo)nacional-cançonetista}

Durante o mês de abril de 2008, efetuei três visitas exploratórias à loja Modern Sound, situada em Copacabana e reconhecida internacionalmente pelo variado acervo de CDs e DVDs musicais. Após recente reforma, no subsolo da loja passou a funcionar uma espécie de "sebo" de discos antigos, com repertório bastante variado e preços entre $R \$ 10$ (álbuns editados no Brasil) e $\mathrm{R} \$ 20$ (importados). 
0 primeiro dia foi dedicado a uma pesquisa bastante simples: comparar a seção de "música portuguesa" do primeiro piso da Modern Sound com a mesma seção no setor de LPs usados.

Concluída essa primeira sondagem, pude perceber como a quantidade de álbuns editados nos últimos dez anos é infinitamente menor do que a dos álbuns que, por estarem numa loja de usados, decerto frequentaram o toca-discos de alguém entre as décadas de 50 e 80 . Além de a quantidade ser menor, também o é a variedade de artistas contemplados: em contraposição à pluralidade do setor de vinis, nas estantes de CDs, o repertório se resume a Mariza, Madredeus, Roberto Leal e coletâneas variadas dedicadas ao fado, não ultrapassando a marca de 20 exemplares. Passível de ser vinculado ao universo do pop/rock, apenas o segundo álbum da banda Toranja, cujas conexões com a música brasileira foram por mim discutidas em outro artigo (MONTEIR0, 2008a).

Tais conclusões preliminares não fugiam ao esperado, pois é sabido que os altos índices de consumo de música portuguesa durante as décadas de 60 a 80 estão relacionados ao vasto mercado representado pelos migrantes que vieram de Portugal na leva dos anos 50, e que a brusca redução desses índices nos últimos dois decênios pode estar vinculada ao fato de tal imaginário simbólico e musical não ter sido atualizado, de modo a parecer atraente para as gerações mais novas, sejam elas lusodescendentes ou não.

A exploração em profundidade do acervo de LPs, durante a segunda e a terceira visitas, foi feita de acordo com 0 seguinte procedimento metodológico de coleta e tabulação dos dados: em uma planilha, registrava o nome do disco e do artista responsável pelo álbum; quando disponíveis, o ano e o local de edição, acrescidos de informações que parecessem relevantes para os objetivos da investigação; por fim, a partir de uma rápida avaliação do material, tentava vinculálo a determinadas classificações genéricas, por mais que elas se revelem problemáticas se tomadas como categorias autônomas?

Há que se levar em consideração ocasionais imprecisões de registro e avaliação dos dados coletados, pois o próprio caráter oportunista de alguns dos álbuns analisados dificultava a obtenção de informações mais detalhadas. De um total de 190 discos disponíveis no acervo, em pouco menos da metade a informação do ano de edição não se encontrava disponível; dos exemplares que fugiam a essa regra, apenas 26 foram editados após a década de 80, com a grande maioria se concentrando entre a segunda metade dos anos 60 e 0 final da década de 70 . Contudo, mesmo nos discos sem data de edição aparente, a partir de características como a arte 
gráfica das capas e a redação dos textos anterior à reforma ortográfica do início dos anos 70, podiase deduzir que sua edição certamente precedia a Revolução dos Cravos. Trinta e três foram editados em Portugal, sete em locais diversos como Itália, Holanda, Estados Unidos e França e os demais consistiam em edições brasileiras.

Pelo menos 67 dos quase 200 discos podiam ser indubitavelmente considerados exemplares de nacional-cançonetismo, podendo esse valor ampliar-se para a casa das centenas se considerarmos as imprecisões. Destes 67 , trinta consistiam em coletâneas de autoria compartilhada por diversos performers (geralmente sob 0 comando de um diretor de orquestra), e a quase totalidade desses discos consistia em edições brasileiras. Dos álbuns de autoria individual, nada mais nada menos do que 20 eram de Roberto Leal, praticamente a discografia completa do artista até 0 início dos anos 90.0 gênero fado era majoritariamente representado por Carlos do Carmo e Amália Rodrigues, que juntos totalizavam cerca de 25 discos; entre estes, era possível encontrar tanto discos editados no Brasil quanto exemplares importados.

No âmbito da (assim nomeada) Música Popular Portuguesa, em contrapartida, dos únicos quatro álbuns disponíveis, dois (Baile no bosque, do Trovante, e Canto da boca, de Sergio Godinho, ambos de 1981) haviam sido editados no Brasil. Dos dois discos vinculados ao gênero pop/rock (ou, melhor dizendo, dos álbuns cujos autores são artistas mormente vinculados ao gênero pop/ rock), o homônimo de Rui Veloso (1983) era uma edição nacional e Mano a mano (1992), do grupo Resistência, importada.

Interessaram-me, sobretudo, as coletâneas, por nelas ficar mais evidente a função propagandística-turística do nacionalcançonetismo. Essa função, na maioria das vezes, ia muito além da seleção do repertório ou do conteúdo expresso nas letras das canções, passando pelo estilo de orquestração empregado, pelo design das capas e por textos de apresentação dos artistas que quase sempre recorriam a elementos da ordem do estereótipo para transmitir ao leitor/ouvinte uma determinada imagem de Portugal.

Em sintonia com essa proposta, a arte gráfica das capas nacional-cançonetistas tende a privilegiar imagens bucólicas associadas à vida no campo e nas aldeias ou monumentos turísticos de imediato reconhecimento (mirantes de Lisboa, a Torre de Belém, o Museu dos Coches ou a Ponte 25 de abril - à época, ainda chamada Ponte Salazar), em detrimento de quaisquer quadros de modernidade associados, por exemplo, aos centros urbanos de Lisboa e Porto. Notadamente nos álbuns que dialogam com o imaginário do fado, reproduzem-se instantâneos de tascas e tavernas, sendo constante a presença da guitarra portuguesa ou dos tradicionais Capas Negras.

A iconografia da guitarra portuguesa também aparece nos discos cujas capas são 
ilustrações. Paradigmática nesse sentido é a coletânea Portugal com amor - 40 sucessos inesquecíveis: Grupo Verde Vinho e convidados

(1978), que curiosamente possui o brasileiro Guto Graça Mello como diretor de produção: vemos, lado a lado, uma garrafa de vinho Mateus Rosé e uma guitarra portuguesa, cujos formatos em muito se assemelham - tanto que, gradativamente, a garrafa se hibridiza com a guitarra e vice-versa. No bojo da garrafa, por sua vez, identifica-se uma reprodução da Torre de Belém.

A contracapa do álbum também oferece material para reflexão: no centro, vemos uma taça de vinho, cuja lateral inferior direita aos poucos se converte num rosto feminino que chora copiosamente. No que tange ao repertório, Portugal com amor apresenta sucessivos medleys temáticos de clássicos cançonetistas, fados e danças folclóricas do Norte do país, em arranjos que misturam sintetizadores, percussão de samba e acordeom, abarcando de "Foi Deus", "Tudo isto é fado" e "Canção do mar" a "Tiroliro", "Bate o pé" e "Arrebita", passando por "Verde vinho", "Uma casa portuguesa" e "Ó tempo volta pra trás".

A vinculação entre Portugal e turismo é tão evidente que alguns discos chegam a sugerir que uma simples audição dos mesmos seria capaz de reproduzir as sensações de uma visita (ou mesmo de um retorno) ao país. Evidentemente, a mediação dos discursos do senso comum faz com que elementos de ordem mítica sejam interpelados, (re)criando um Portugal de sonho, quase inalcançável.

Passageiros para Portugal, boa viagem! [...] Vamos viver o doce enlevo de esplêndidos vôos panorâmicos sobre essa pátria irmã e amiga. Nas asas da música sentiremos 0 calor da afeição recíproca que nos aproxima. E visitaremos Lisboa. E entraremos, deslumbrados, em Coimbra. E avistaremos tricanas às margens do Tejo. E beberemos desse lirismo apaixonante que Portugal inventou. E cantaremos fados tristes como a distância e a saudade. E canções alegres como 0 amor e a ventura. E sonharemos assim, de olhos abertos e felizes. (Seleções de Portugal - volume III; s/d)

Não é preciso ir a Coimbra para sentir o rumor das margens do Mondego [...] nem evocar seus monumentos e portagens, ao se ouvir Alberto Ribeiro. [...] Quem provou os pastéis de Tentugal, que as raparigas de saia franzida à cintura e pernas ao vento oferecem em gorgeios lacrimosos quando a estação da Velha Coimbra regorgita de campônios, capas negras e tricanas - e depois escuta Alberto Ribeiro aqui de longe sente outra vez, muito de perto, no coração e na alma, a Coimbra do choupal com seus queixumes e tantas relíquias históricas. (Alberto Ribeiro, a voz de Portugal; s/d)

Quando [Francisco José] cantou, minha infância surgiu, de repente, inteirinha, naquela "adega", onde eu não sentira, ao entrar, parentesco com a adega da minha casa na Beira. [...] Francisco José cantava [...], Lisboa vinha na voz dele, [...] para que ele afagasse [...] sete colinas banhadas de sol, sete pulsações de um coração iluminado pela saudade. [...] Nada me faria supor que eu iria para longe, muito longe, sem deixar 0 Rio de Janeiro. (A volta do fabuloso Francisco José, 1969?)

Não ocasionalmente, o nome da empresa, entidade ou organização patrocinadora do 
álbum é mencionado ${ }^{8}$. No caso da TAP, até hoje a principal companhia aérea a operar no trecho Brasil-Portugal, por exemplo, a menção podia se dar de forma menos ou mais explícita. $\mathrm{Na}$ contracapa do álbum Roberto Leal Especial gravado ao vivo no Casino Estoril (1984) em meio a uma coleção de fotografias nas quais vemos 0 artista em plena Praça do Comércio lisboeta, subindo as escadarias de uma viela da Alfama cercado de criancinhas e abraçando uma senhora idosa vestida de preto, encontramos o cantor dentro de um avião, acompanhado de uma legenda mais do que esclarecedora: "Um agradecimento àquela que tornou este sonho realidade: TAP - Air Portugal". Já no peculiaríssimo disco De Ipanema à Alfama (1971), cujo repertório constitui-se de uma improvável alternância entre fados e canções da bossa-nova, a fotografia de capa nos apresenta a um apaixonado casal (luso-brasileiro?) cujo cenário, ao fundo, é emoldurado pela lateral de um avião da companhia.

\section{Considerações finais}

Se todo olhar em direção a um Outro nunca é desinteressado ou neutro, sempre implicando algum tipo de recorte, o olhar turístico parece conformar um enquadramento repleto de particularidades. Ao turista, na maior parte das vezes, falta tempo ou interesse para conhecer em profundidade a cultura desse Outro.

Diante de uma complexidade impossível de decodificar, durante uma estadia de poucos dias ou semanas, tais recortes acabam se tornando espécies de atalhos estratégicos, que ao final do percurso fornecem a volátil impressão de um entendimento pleno. Museus que catalogam determinados episódios da história de um país; monumentos carregados de significados socialmente construídos; lugares de memória capazes de fixar a lembrança de eventos associados a um tempo distante; sem esquecer dos imprescindíveis guias de viagem, que otimizam a busca do turista selecionando as etapas do trajeto consideradas impossíveis de contornar (NORA, 1984).

Com a progressiva desmaterialização da economia, apontada, entre outros autores, por Harvey (1994), Featherstone (1995) e Castells (1999), no contexto do capitalismo tardio, 0 consumo de signos e a valorização da experiência imaterial passam a legitimar, mais do que nunca, 0 incremento de atividades turísticas possuidoras de uma proposta algo diferenciada. Não basta mais visitar os pontos-chave determinados por um roteiro inalterado há três décadas: é preciso viver o lugar, acumular sensações, percorrer circuitos ausentes dos guias de turismo, mas constantes na cartografia cotidiana daquele espaço. 
0 olhar turístico não é algo negativo em si. Os problemas começam quando ele se torna 0 único discurso mediador entre Eu e o Outro, e no que concerne aos fluxos simbólicos entre Portugal e Brasil, às vezes tem-se a impressão de que alguns estereótipos de uma certa cultura portuguesa acabam sendo percebidos como sinônimos da única cultura portuguesa possível. 0 resultado é que, diante da pluralidade do cenário musical português contemporâneo, 0 discurso hegemônico brasileiro ainda associa Portugal ao fado, às danças folclóricas ou ao imaginário nacional-cançonetista, dificultando sobremaneira a penetração de gêneros vinculados ao universo do pop/rock ou da música eletrônica em nosso mercado fonográfico.

Parece evidente que 0 objeto da reflexão que aqui se encerra contribui no sentido de problematizar o modo como um gênero musical tão deslegitimado como o nacionalcançonetismo atuou, em sintonia com outras variáveis, no sentido de perpetuar um imaginário até hoje interpelado na nossa maneira de pensar Portugal. E se mesmo a música popular midiática posterior à Revolução de Abril, ora nomeada como ligeira ora como moderna, constitui-se num diálogo com essa matriz nacional-cançonetista, talvez seja o momento de colocar sob rasura determinados preconceitos de ordem valorativa, a fim de que novos olhares sobre 0 universo da cultura midiática portuguesa possam ser adequadamente lançados.

\section{Referências}

ALVES, Vera Marques. "A poesia dos simples": arte popular e nação no Estado Novo. Etnográfica - revista do Centro de Estudos de Antropologia Social do ISCTE, Lisboa, v.1, n.11, p. 63-89, maio 2007.

BORGES, Ana Lúcia. Fado moderno à beira do Tejo. O Globo, Rio de Janeiro, p. 24-33 (Boa Viagem), 31 jul. 2008.

CASTELLS, Manuel. A sociedade em rede, vol. 1 - A era da informação: economia, sociedade e cultura. São Paulo: Paz e Terra, 1999.

CORREIA, Mario. Música popular portuguesa: um ponto de partida. Coimbra: Centelha; Mundo da Canção, 1984.

FEATHERSTONE, Mike. Cultura de consumo e pósmodernismo. São Paulo: Studio Nobel, 1995.

FRITH, Simon. Performing rites: on the value of popular music. Cambridge: Harvard University Press, 1996.

GRANJA, Paulo Jorge. 0 leão da Estrela. In: FERREIRA, Carolin Overhoff (org.). 0 cinema português através dos seus filmes. Porto: Campo das Letras, 2007. p. 53-61.

HARVEY, David. Condição pós-moderna: uma pesquisa sobre as origens da mudança cultural. São Paulo: Loyola, 1994.

HONRAD0, Alexandre. As sete colinas. Viagem e turismo - especial Isto é Portugal, São Paulo, ed. 151-F, p. 22, maio 2008.

JANOTTI JR., Jeder. Aumenta que isso aí é rock'n'roll: mídia, gênero musical e identidade. Rio de Janeiro: E-Papers, 2003.

MONTEIR0, Tiago José Lemos. Muito além da 'Casa Portuguesa': uma análise dos intercâmbios musicais populares massivos entre Brasil e Portugal. Matrizes - revista do programa de Pós-Graduação em Ciências da Comunicação da Universidade de São Paulo, São Paulo, n. 1, p. 227-241, jul-dez 2008a. 
Cartografias do imaginário navegante:

reflexões sobre a identidade narrativa diaspórica, 0 "senso comum mítico" e nosso (des)conhecimento da cultura portuguesa contemporânea. In: COLÓQUIO BINACIONAL BRASIL-PORTUGAL, 1.; CONGRESSO BRASILEIRO DE CIÊNCIAS DA COMUNICAÇÃO, 21., 2008, Natal. Anais... Natal: Intercom, 2008b. Disponível em: <http://www.intercom.org.br/papers/ nacionais/2008/resumos/R3-0208-2.pdf $>$. Acesso em: 27 jan. 2009.

NORA, Pierre. Entre a memória e a história - os lugares de memória. In: . Les lieux de mémoire.

Tradução: Patrícia Farias. Paris: Gallimard, 1984.

PORTAS, Moreno. Portugal barato \& Quase nossa casa. Minha viagem, São Paulo, ed. 4, p. 48-57, jun. 2008. REIS, Patrícia. A cidade dos anjos. Viagem \& turismo - especial Isto é Portugal, São Paulo, ed. 151-F, p. 21, maio 2008.

QUEIROZ, José Eça de. Do castelo a Belém. Viagem \& turismo - especial Isto é Portugal, São Paulo, ed. 151-F, p. 18-19, maio 2008.

SALAZAR, Tiago. Alma. Viagem \& turismo - especial Isto é Portugal, São Paulo, ed. 151-F, p. 17-18, maio 2008.

SANTOS, Boaventura de Sousa. Pela mão de Alice: o social e o político na pós-modernidade. São Paulo: Cortez, 2006.

SHAW, Lisa. A aldeia da roupa branca. In: FERREIRA, Carolin Overhoff (org.). 0 cinema português através dos seus filmes. Porto: Campo das Letras, 2007. p. 47-51. 


\section{"How beautiful my little village is": the role of popular music genres in the construction of a mythical image of Portugal}

\section{Abstract}

This paper aims to investigate how certain popular music genres helped to reinforce a mythical image of Portugal, linked to its condition of touristic destination or oriented to Portuguese communities in other countries, especially in the last ten years of Salazarism (1964-1974) and the following decade. Initially, I try to establish a connection between the symbolic imaginary which has become hegemonic on many representations of Portugal that circulate in Brazilian touristic magazines and newspapers, especially the ones focused on the city of Lisbon. Furthermore, I discuss how our lack of knowledge about Portuguese contemporary music production can be related to the predominance of musical formats usually known as nacional-cançonetismo, which reproduce some stereotypes about Portuguese culture with political and commercial intentions.

\section{Keywords}

Brazil-Portugal relations. Popular music. Nacionalcançonetismo. Stereotype. Salazarism.
“¡Cómo es linda mi aldea!”: el papel de los generos musicales masivos en la construcción de una imagén mítica de Portugal

\section{Resumen}

El objetivo de este artículo es investigar en qué medida algunos géneros musicales populares masivos y mediáticos actuaran en el sentido de reforzar una determinada imagen mítica de Portugal, asociada a la condición de destino turístico o direccionada a la comunidad emigrante residente en el exterior, sobre todo durante las últimas décadas del Salazarismo (1964-1974) y también a lo largo del decenio posterior. Inicialmente, se buscó establecer una conexión entre el imaginario simbólico consagrado en esta época y las representaciones hegemónicas sobre Portugal que hoy circulan en las revistas y en los cuadernos turísticos, principalmente en aquellos cuyo foco es la capital Lisboa. En un según momento, teniendo en vista nuestro (des) conocimiento de la producción musical portuguesa contemporánea, discuto cómo la predominancia de formatos encuadrados en aquello que se consagró como "nacional-cançonetismo" está íntimamente relacionada a la perpetuación de algunos "recortes" estereotipados sobre Portugal, asociada, casi siempre, a iniciativas de carácter político y mercadológico.

\section{Palabras clave}

Relaciones Brasil-Portugal. Música popular masiva. Nacional-cançonetismo. Estereotipo. Salazarismo. 


\section{Expediente}

A revista E-Compós é a publicação científica em formato eletrônico da Associação Nacional dos Programas de Pós-Graduação em Comunicação (Compós). Lançada em 2004, tem como principal finalidade difundir a produção acadêmica de pesquisadores da área de Comunicação, inseridos em instituições do Brasil e do exterior.
E-COMPÓS I www.e-compos.org.br I E-ISSN 1808-2599

Revista da Associação Nacional dos Programas de Pós-Graduação em Comunicação. Brasília, v.12, n.1, jan./abr. 2009.

A identificação das edições, a partir de 2008 passa a ser volume anual com três números.

\section{CONSELHO EDITORIAL}

\section{Afonso Albuquerque}

Universidade Federal Fluminense, Brasil

Alberto Carlos Augusto Klein

Universidade Estadual de Londrina, Brasi

Alex Fernando Teixeira Primo

Universidade Federal do Rio Grande do Sul, Brasil

\section{Alfredo Vizeu}

Universidade Federal de Pernambuco, Brasil

Ana Carolina Damboriarena Escosteguy

Pontifícia Universidade Católica do Rio Grande do Sul, Bras

Ana Silvia Lopes Davi Médola

Universidade Estadual Paulista, Brasil

André Luiz Martins Lemos

Universidade Federal da Bahia, Brasil

Ângela Freire Prysthon

Universidade Federal de Pernambuco, Brasil

Antônio Fausto Neto

Universidade do Vale do Rio dos Sinos, Brasil

Antonio Carlos Hohlfeldt

Pontifícia Universidade Católica do Rio Grande do Sul, Brasil

Arlindo Ribeiro Machado

Universidade de São Paulo, Brasil

César Geraldo Guimarães

Universidade Federal de Minas Gerais, Brasil

Cristiane Freitas Gutfreind

Pontifícia Universidade Católica do Rio Grande do Sul, Brasil

Denilson Lopes

Universidade Federal do Rio de Janeiro, Brasil

Eduardo Peñuela Cañizal

Universidade Paulista, Brasi

Erick Felinto de Oliveira

Universidade do Estado do Rio de Janeiro, Brasil

Francisco Menezes Martins

Universidade Tuiuti do Paraná, Brasil

Gelson Santana

Universidade Anhembi/Morumbi, Brasi

Hector Ospina

Universidad de Manizales, Colômbia

leda Tucherman

Universidade Federal do Rio de Janeiro, Brasil

Itania Maria Mota Gomes

Universidade Federal da Bahia, Brasil

Janice Caiafa

Universidade Federal do Rio de Janeiro, Brasil

Jeder Silveira Janotti Junior

Universidade Federal da Bahia, Brasil

\section{João Freire Filho}

Universidade Federal do Rio de Janeiro, Brasil

John DH Downing

University of Texas at Austin, Estados Unidos

José Luiz Aidar Prado

Pontifícia Universidade Católica de São Paulo, Brasil

José Luiz Warren Jardim Gomes Braga

Universidade do Vale do Rio dos Sinos, Brasil

Juremir Machado da Silva

Pontifícia Universidade Católica do Rio Grande do Sul, Brasil

Lorraine Leu

University of Bristol, Grã-Bretanha

Luiz Claudio Martino

Universidade de Brasília, Brasil

Maria Immacolata Vassallo de Lopes

Universidade de São Paulo, Brasil

Maria Lucia Santaella

Pontifícia Universidade Católica de São Paulo, Brasil

Mauro Pereira Porto

Tulane University, Estados Unidos

Muniz Sodre de Araujo Cabral

Universidade Federal do Rio de Janeiro, Brasil

Nilda Aparecida Jacks

Universidade Federal do Rio Grande do Sul, Brasil

Paulo Roberto Gibaldi Vaz

Universidade Federal do Rio de Janeiro, Brasil

Renato Cordeiro Gomes

Pontifícia Universidade Católica do Rio de Janeiro, Brasil

Ronaldo George Hela

Universidade do Estado do Rio de Janeiro, Brasil

Rosana de Lima Soares

Universidade de São Paulo, Brasil

Rossana Reguillo

Instituto Tecnológico y de Estudios Superiores do Occidente, México

Rousiley Celi Moreira Maia

Universidade Federal de Minas Gerais, Brasil

Sebastião Carlos de Morais Squirra

Universidade Metodista de São Paulo, Brasi

Simone Maria Andrade Pereira de Sá

Universidade Federal Fluminense, Brasil

Suzete Venturelli

Universidade de Brasília, Brasil

Valério Cruz Brittos

Universidade do Vale do Rio dos Sinos, Brasil

Veneza Mayora Ronsini

Universidade Federal de Santa Maria, Brasil

Vera Regina Veiga França

Universidade Federal de Minas Gerais, Brasil
COMISSÃO EDITORIAL

Ana Gruszynski I Universidade Federal do Rio Grande do Sul, Brasil

Rose Melo Rocha I Escola Superior de Propaganda e Marketing, Brasil

CONSULTORES AD HOC

Alberto Schneider I Visitante Tokyo University

Alexandre Rocha da Silva I Universidade Federal do Rio Grande do Sul, Brasil

Fernanda Bruno I Universidade Federal do Rio de Janeiro, Brasil

Ida Stumpf I Universidade Federal do Rio Grande do Sul, Brasil

Kati Caetano I Universidade Tuiuti do Paraná, Brasil

Laura Cánepa I Universidade Anhembi Morumbi, Brasi

Malena Contrera I Universidade Paulista, Brasil

Sandra Gonçalves I Universidade Federal do Rio Grande do Sul, Brasil

Vicente Gosciola I Universidade Anhembi Morumbi, Brasil

REVISÃO DE TEXTO E TRADUÇÃo I Everton Cardoso

EDITORAÇ̃̃o ELETRÔNICA I Raquel Castedo
COMPós I www.compos.org.br

Associação Nacional dos Programas de Pós-Graduação em Comunicação

Presidente

Erick Felinto de Oliveira

Universidade do Estado do Rio de Janeiro, Brasil erickfelinto@uol.com.br

Vice-presidente

Ana Silvia Lopes Davi Médola

Universidade Estadual Paulista, Brasil

asilvia@faac.unesp.br

Secretária-Geral

Denize Correa Araújo

Universidade Tuiuti do Paraná, Brasil

denizearaujo@hotmail.com 